J. Dairy Sci. 92:6011-6022

doi:10.3168/jds.2009-2374

(c) American Dairy Science Association, 2009.

\title{
The effect of dry period duration and dietary energy density on milk production, bioenergetic status, and postpartum ovarian function in Holstein-Friesian dairy cows
}

\author{
M. A. de Feu, ${ }^{*} \dagger$ A. C. O. Evans, $†$ P. Lonergan, $†$ and S. T. Butler*1 \\ ${ }^{*}$ Teagasc, Moorepark Dairy Production Research Centre, Fermoy, Co. Cork, Ireland \\ †School of Agriculture, Food Science and Veterinary Medicine, University College Dublin, Belfield, Dublin 4, Ireland
}

\begin{abstract}
Following parturition, it is typical for dairy cows to enter a period of negative energy balance and body condition loss to support mammary milk synthesis; this is associated with compromised reproductive performance. Alternative management strategies during the prepartum (dry) and early postpartum periods may ameliorate this loss. Forty mature Holstein-Friesian cows were assigned to 1 of 2 dry period treatments [standard 8-wk dry period (SDP) or no planned dry period (NDP)] and 1 of 2 dietary energy density treatments [standard TMR (STMR) or high-quality TMR (HTMR)]. Milk yield during wk 1 to 12 postpartum was reduced in cows assigned to the NDP treatment. Energy balance and body condition score (BCS) during wk 1 to 4 postpartum were increased in cows assigned to the NDP treatment compared with the cows assigned to the SDP treatment, and BCS increased from wk 5 to 12 postpartum in the NDP cows compared with the SDP cows. During the first 12 wk postpartum, cows assigned to the HTMR diet had greater milk yield and reduced milk fat concentration compared with the cows assigned the STMR diet. The BCS was greater from wk 5 to 12 postpartum in HTMR cows compared with STMR cows. During the period from wk -3 to +3 relative to parturition, circulating concentrations of insulin, glucose, and IGF-I were greater in cows in the NDP treatment compared with cows in the SDP treatment. Cows assigned to the HTMR diet had greater circulating insulin and glucose concentrations compared with the STMR cows from wk -3 to +3 relative to parturition. The first postpartum ovulation occurred earlier for cows in the NDP treatment compared with cows in the SDP treatment (16.9 vs. $24.8 \mathrm{~d}$ postpartum. Cows assigned to the STMR diet tended to have a higher conception rate to first service compared with
\end{abstract}

Received May 12, 2009.

Accepted August 10, 2009.

${ }^{1}$ Corresponding author: stephen.butler@teagasc.ie cows assigned to the HTMR diet. Energy balance and metabolic status can be improved by either eliminating the dry period or by feeding a higher energy diet, but effects on the reproductive axis appear to be different. Key words: dry period, feeding level, energy balance, resumption of cyclicity

\section{INTRODUCTION}

Reproductive efficiency in high-yielding dairy cows has decreased in recent decades (Royal et al., 2000; Butler, 2003; Evans et al., 2006). Intensive genetic selection for increased milk production has led to remarkable improvements in milk yield per cow, but has also been associated with a worldwide decline in dairy cow fertility. It has been demonstrated that a negative correlation between genetic merit for milk yield and reproductive performance exists (van Arendonk et al., 1989; Pryce et al., 1997; Pryce and Veerkamp, 2001).

The onset of lactation in dairy cattle causes a dramatic increase in mammary glucose requirements, and marked changes in whole-body metabolism are required to accommodate these needs. Following parturition, high-producing dairy cows typically experience a variable period of negative energy balance (NEB) because DMI is inadequate to fully meet the increasing energetic requirements of milk production. The severity and duration of NEB experienced in early lactation affects the postpartum interval to first ovulation and has a detrimental effect on subsequent likelihood of conception (Villa Godoy et al., 1988; Butler and Smith, 1989). A delay in the onset of ovulatory ovarian activity limits the number of estrous cycles before breeding, reducing the likelihood of conception and increasing the number of days open (Butler, 2003). Nutritional approaches to overcoming early-lactation NEB have been largely unsuccessful. This is primarily because of the inherent drive to produce additional milk in response to additional nutrient intake - the hallmark of the modern Holstein-Friesian dairy cow. The metabolic and endocrine milieu that ensues during NEB is antagonistic to 
Table 1. Ingredient and nutrient composition of standard TMR (STMR) and high-quality TMR (HTMR) diets

\begin{tabular}{lcc}
\hline Item & STMR & HTMR \\
\hline Diet ingredient & & \\
Grass silage & 0.50 & 0.20 \\
Barley & 0.35 & 0.24 \\
Brewers grains and beet pulp mix & - & 0.30 \\
Soybean meal & 0.13 & 0.10 \\
Soyhulls & - & 0.15 \\
Vitamins and minerals ${ }^{1}$ & 0.02 & 0.01 \\
Nutrient composition (DM basis) & 892 & 904 \\
DM (g/kg) (UFL ${ }^{2} / \mathrm{kg}^{2}$ of DM) & 0.96 & 1.02 \\
Net energy & 71 & 65 \\
Ash (g/kg of DM) & 164 & 178 \\
CP (g/kg of DM) & 385 & 415 \\
NDF (g/kg of DM) & 2.9 & 3.3 \\
Oil (acid hydrolysis; \%) & \\
\hline
\end{tabular}

${ }^{1}$ Vitamin and mineral mix: $15 \mathrm{~g} / \mathrm{kg}$ of DiCa P, $8 \mathrm{~g} / \mathrm{kg}$ of limestone flour, $5 \mathrm{~g} / \mathrm{kg}$ of salt, $2.5 \mathrm{~g} / \mathrm{kg}$ of Cal-Mag, $80 \mathrm{~g}$ of manganous oxide, $200 \mathrm{~g}$ of copper sulfate, $125 \mathrm{~g}$ of zinc oxide, $18 \mathrm{~g}$ of potassium iodate, $20 \mathrm{~g}$ of soduim selenite $(4.6 \%), 10 \mathrm{~g}$ of cobalt sulfate, $8 \mathrm{MIU} / \mathrm{t}$ of vita$\min \mathrm{A}, 2 \mathrm{MIU} / \mathrm{t}$ of vitamin $\mathrm{D}_{3}, 15,000 \mathrm{IU} / \mathrm{t}$ of vitamin $\mathrm{E}$.

${ }^{2} \mathrm{UFL}=$ unité fourragère lait; unit of net energy, equivalent to $1 \mathrm{~kg}$ of standard air-dried barley.

the resumption of ovulatory ovarian activity (Butler et al., 2006), resulting in anestrus and reduced conception rates.

It is generally accepted that a dry period of 50 to $60 \mathrm{~d}$ is required to maximize milk production in the subsequent lactation (for recent reviews, see Bachman and Schairer, 2003; Annen et al., 2004; and Grummer and Rastani, 2004). There has recently been substantial interest in decreasing the duration of the dry period. Cows that avoid severe decreases in DMI prepartum have improved energy balance (EB) pre- and postpartum (Grummer, 1995). Recently, it has been demonstrated that omitting the dry period results in dramatic alterations in EB and metabolic profiles (Rastani et al., 2005). The current study was carried out to examine the effect of dry period duration and dietary energy density on milk production, DMI, EB, metabolic status, and indicators of reproductive efficiency. Specifically, postpartum follicular dynamics and reproductive hormone profiles were examined to assess the effects of dry period duration and feeding level on the resumption of cyclicity.

\section{MATERIALS AND METHODS}

\section{Animals and Experimental Design}

This experiment was a completely randomized block design with a $2 \times 2$ factorial arrangement of treatments. Forty mature Holstein-Friesian cows were blocked on the basis of expected calving date, previous lactation yield, BW, and BCS, and were randomly as- signed to 1 of 2 dry period treatments [standard 8-wk dry period (SDP) or no planned dry period (NDP)] and 1 of 2 dietary energy density treatments [standard TMR (STMR) or high-quality TMR (HTMR)]. Cows assigned to the SDP treatment were fed ad libitum grass silage prepartum and either the STMR or the HTMR diet during the first 12 wk postpartum. Cows assigned to the NDP treatment were fed the STMR or HTMR diet during the dry period and the first $12 \mathrm{wk}$ postpartum. If prepartum daily milk yield decreased below $2 \mathrm{~kg} / \mathrm{d}$ for cows in the NDP treatments, milking was discontinued for the remainder of the prepartum period. Actual dry period lengths (mean \pm SEM) were $62.1 \pm 1.9 \mathrm{~d}$ and $6.3 \pm 1.7 \mathrm{~d}$ for cows in the SDP and NDP treatments, respectively. Two cows were dropped from the SDP treatment and 2 cows were dropped from the NDP treatment because their dry periods were too short or too long, respectively, or because of illnesses unrelated to the study.

\section{Animal Measurements}

Cows were housed in freestall housing from 4 wk before expected calving until $12 \mathrm{wk}$ postpartum. Cows were milked twice daily (prepartum and postpartum) and milk production was recorded at each milking using electronic milk meters (Dairymaster, Causeway, Co. Kerry, Ireland). Milk composition (protein, fat, and lactose, $\mathrm{g} / \mathrm{kg}$ ) was measured once per week by nearinfrared reflectance spectroscopy (MilkoScan 605; Foss Electric, Hillerød, Denmark). Solids-corrected milk yield was calculated using the equation of Tyrrell and Reid (1965).

Daily measurements of DMI were recorded using the Griffith-Elder MealMaster system (Griffith Elder \& Co Ltd., Suffolk, UK). The ingredients for all diets were sampled weekly. Silage pH was measured on the juice pressed from the silage using a glass electrode and a pH meter (pHM2 standard pH meter-radiometer, Radiometer, Copenhagen, Denmark). The dry matter, CP, NDF, ash, starch, and oil contents of the feed samples were analyzed as described by McNamara et al. (2003). The ingredient and nutrient composition of the diets is summarized in Table 1.

Body weight and BCS were measured weekly by the same technician. Energy balance was estimated as the difference between energy intake and the sum of energy requirements for maintenance and milk production, using the French net energy system (Jarrige, 1989). This system uses unité fourragère lait (UFL) as the unit of net energy, which is equivalent to $1 \mathrm{~kg}$ of standard air-dried barley. The following equations were used to determine the energy required for maintenance and output in milk (O'Mara, 1997): 
energy required for maintenance $(\mathrm{UFL} / \mathrm{d})=$

$$
1.4+0.6 \mathrm{BW} / 100 \text {, and }
$$

energy requirement for milk $(\mathrm{UFL} / \mathrm{kg}$ of milk) $=$

$$
0.0054 \mathrm{FC}+0.0031 \mathrm{PC}+0.0028 \mathrm{LC}-0.015,
$$

where $\mathrm{FC}=$ fat concentration $(\%), \mathrm{PC}=$ protein concentration (\%), and LC = lactose concentration (\%).

\section{Blood Sampling and Analysis}

Blood samples were collected 3 times/wk for the final 3 wk prepartum, daily for the first $28 \mathrm{~d}$ postpartum, and once every 2 wk thereafter until d 84 of lactation. All blood samples were collected from the coccygeal blood vessel into $10-\mathrm{mL}$ lithium heparin vacutainers (Becton Dickinson, Plymouth, UK). The blood samples were centrifuged at $2,000 \times g$ for $15 \mathrm{~min}$ at $5^{\circ} \mathrm{C}$. The plasma was harvested and decanted into $1.5-\mathrm{mL}$ aliquots and stored at $-20^{\circ} \mathrm{C}$ until further analyses.

Plasma samples were analyzed for indicators of metabolic status from d -12 to 84 relative to parturition. Glucose, NEFA, urea, and BHBA concentrations were analyzed by enzymatic colorimetry using appropriate kits (NEFA kit supplied by Wako Chemicals, GmbH, Nissanstraße, Germany; glucose, BHBA, and urea kits supplied by ABX Mira, Montpellier, France) and an ABX Mira autoanalyser (ABX Mira).

Plasma insulin concentrations were determined using a solid-phase fluoroimmunoassay (AutoDELFIA, PerkinElmer Life and Analytical Science, Turku, Finland) using appropriate kits (Unitech BD Ltd., Dublin, Ireland). The inter- and intraassay coefficients of variation were 10.9 and $4.5 \%$, respectively $(\mathrm{n}=3)$.

Circulating IGF-I concentrations were quantified using a validated double-antibody radioimmunoassay following ethanol-acetone-acetic acid extraction (Enright et al., 1989). Recombinant human IGF-I (R\&D Systems Europe, Abingdon, UK) was used as a standard and to generate iodinated tracer. The assay was carried out as described by Spicer et al. (1990). Inter- and intraassay coefficients of variation were 27.5 and $14.9 \%$, respectively $(\mathrm{n}=8)$. Circulating FSH concentrations were analyzed in daily plasma samples collected from the day of parturition until 8 DIM using a validated radioimmunoassay (Crowe et al., 1997). The inter- and intraassay coefficients of variation were 5.7 and $9.5 \%$, respectively $(\mathrm{n}=3)$.

Circulating estradiol (E2) concentrations were measured in blood samples collected on consecutive days during development of the dominant follicle of the first postpartum follicle wave. If ovulation occurred, plasma
E2 concentrations were measured on each of the $7 \mathrm{~d}$ immediately before ovulation. If the cow had a dominant follicle that underwent atresia or became cystic, E2 concentrations were measured in blood samples collected daily from emergence of the dominant follicle until the point of maximum observed follicle diameter. The concentration of E2 in plasma was determined by radioimmunoassay following extraction (Prendiville et al., 1995) using E2 MAIA kits (Biostat, Stockport, UK). Inter- and intraassay coefficients of variation were 21.5 and $13.1 \%$, respectively $(\mathrm{n}=4)$. For all hormone assays, each treatment was equally represented in each assay and all samples for a cow on a given treatment were completed in a single assay.

\section{Postpartum Ultrasound Evaluation and Reproductive Management}

Ovarian follicular activity was examined by linear array ultrasonography (Aloka 900; 7.5-MHz transrectal transducer, Aloka Ltd., Tokyo, Japan) thrice weekly beginning on $\mathrm{d} 8$ to 10 postpartum and continuing until first ovulation. Ovulation was deemed to have occurred following the disappearance of a dominant follicle and the subsequent appearance of a corpus luteum. The size of a large follicle was determined by finding the average diameter in 2 directions at right angles on a single frozen image. The number of small $(<5 \mathrm{~mm})$, medium $(5-10 \mathrm{~mm})$, and large $(>10 \mathrm{~mm})$ follicles were recorded for each ovary at every ultrasound examination. If ovulation had not occurred by d 60 postpartum, cows were treated with the following hormone program to commence cycling: GnRH (10 $\mu \mathrm{g}$ buserelin; Receptal, Intervet Ireland, Dublin) and controlled internal drugreleasing insert (CIDR) insertion (InterAg, Hamilton, New Zealand) on d 0; $\mathrm{PGF}_{2 \alpha}(500 \mu \mathrm{g}$ cloprostenol sodium; Estrumate, BP (Vet) Coopers, Berkhamsted, UK) on d 7; and CIDR removal on d 9. Ovulation was confirmed using transrectal ultrasonography to visualize a corpus luteum approximately $7 \mathrm{~d}$ after CIDR removal. Initiation of breeding commenced on a calendar mating start date (November 27, 2005). Tail paint was used as a heat detection aid, and all cows were inseminated using AI following observation of standing estrus, or removal of tail paint, or both. Pregnancy status was determined using transrectal ultrasonography on d 30 through 36 and d 60 through 66 post-AI. Visualization of a fluidfilled uterine horn with the presence of a viable embryo was used as positive indication of pregnancy.

\section{Data Handling and Statistical Analysis}

Daily measurements of milk yield, DMI, and EB were collapsed into weekly means. The prepartum BW and 
Table 2. The effect of dry period duration and dietary energy density on milk production and composition for wk 1 to 12 of lactation

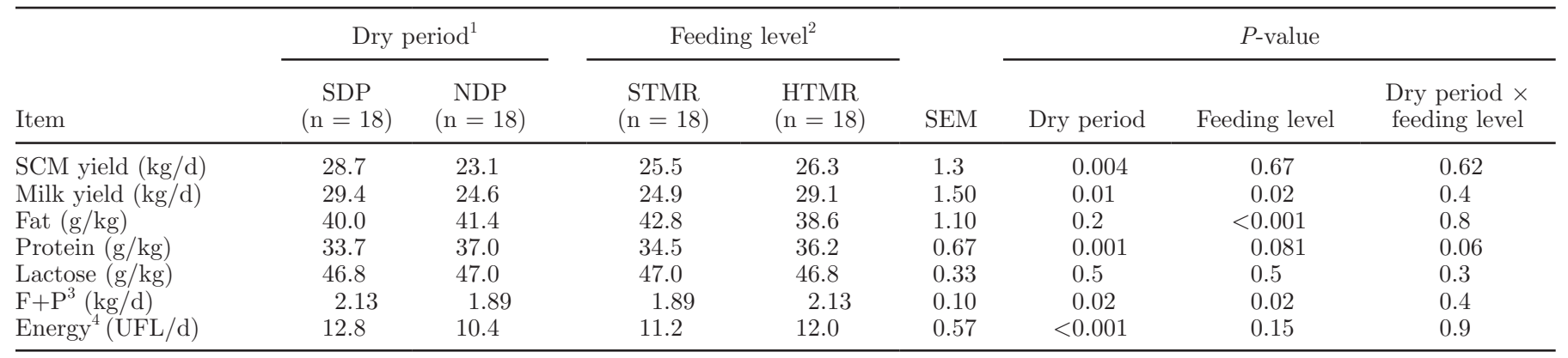

${ }^{1} \mathrm{SDP}=$ standard 8-wk dry period; NDP $=$ no planned dry period.

${ }^{2} \mathrm{STMR}=$ standard TMR; HTMR $=$ high-quality TMR.

${ }^{3} \mathrm{~F}+\mathrm{P}=$ fat and protein yield.

${ }^{4}$ Milk energy output; UFL = unité fourragère lait, unit of net energy, which is equivalent to $1 \mathrm{~kg}$ of standard air-dried barley.

BCS data were lost because of a technical failure in the electronic recording system. The EB, BCS, and DMI data for each cow were divided into 2 periods; wk 1 to 4 postpartum and wk 5 to 12 postpartum. Milk yield, milk composition, SCM, DMI, EB, BW, and plasma FSH data were analyzed as repeated measures using the MIXED procedure of SAS (version 9.1, SAS Institute, Cary, NC) with an autoregressive covariance structure. The fixed effects included in the model were dry period, feeding level, time (day or week), and all possible interactions. Block was included as a random effect. Conception rate data were analyzed using Fisher's exact test.

The metabolite and insulin data for each cow were divided into 2 time points; the transition period lasted from 3 wk before parturition to 3 wk postpartum and the posttransition period lasted from 4 wk to $12 \mathrm{wk}$ postpartum. The IGF-I data was analyzed in a similar manner, with the exception that the posttransition period was wk 4 to 9 postpartum. The insulin, IGF-I, and metabolite data were analyzed as repeated measures using the MIXED procedure of SAS (version 9.1, SAS Institute) with an autoregressive covariance structure with the same fixed and random effects as outlined above.

The peak circulating concentration of FSH during the first $10 \mathrm{~d}$ postpartum and the peak E2 concentration during the first postpartum follicular wave were analyzed using the MIXED procedure of SAS (version 9.1, SAS Institute). Fixed effects included in the model were dry period, feeding level, and the interaction between dry period and feeding level. Block was included as a random effect. The relationship between the total number of small $(<5 \mathrm{~mm})$, medium $(5-10 \mathrm{~mm})$, and large $(>10 \mathrm{~mm})$ follicles recorded at the first postpartum ultrasound examination, peak circulating FSH concentrations, and the number of days postpartum when peak circulating FSH concentration occurred was analyzed using Pearson correlation coefficients.

\section{RESULTS}

There was no interaction between dry period duration and feeding level for most variables, so both factors are presented separately; where interactions were observed, these are reported.

\section{Milk Production and Composition}

Milk production data are summarized in Table 2. The SCM yield was reduced by $19.5 \%$ in cows assigned to the NDP treatment during the first 12 wk of lactation compared with cows assigned to the SDP treatment $(P$ $=0.004$ ). The yield of fat and protein was reduced by $11.3 \%$ in the NDP cows compared with the SDP cows $(P=0.02)$. Cows assigned to the NDP treatment had greater $(P=0.001)$ milk protein concentration compared with cows assigned to the SDP treatment.

Milk yield was $16.9 \%$ greater $(P=0.02)$ and the yield of fat and protein was increased by $12.7 \%(P=$ 0.02) in cows fed the HTMR diet compared with those fed the STMR diet. Milk fat concentration was significantly reduced $(P<0.001)$ for cows on the HTMR diet, resulting in an increase in SCM yield of only $3.1 \%$ compared with cows on the STMR diet. The HTMR treatment tended $(P=0.08)$ to increase milk protein concentration.

\section{$D M I, E B$, and BCS}

The DMI, EB, and BCS data are summarized in Table 3. Cows assigned to the NDP treatment had greater $(P$ $<0.001)$ prepartum DMI compared with cows assigned to the SDP treatment, but there was no difference in 
Table 3. The effect of dry period duration and dietary energy density on DMI, BCS, and energy balance (EB) for wk 1 to 4 and 5 to 12 of lactation

\begin{tabular}{|c|c|c|c|c|c|c|c|c|}
\hline \multirow[b]{2}{*}{ Item } & \multicolumn{2}{|c|}{ Dry period $^{1}$} & \multicolumn{2}{|c|}{ Feeding level $^{2}$} & \multirow[b]{2}{*}{ SEM } & \multicolumn{3}{|c|}{$P$-value } \\
\hline & $\begin{array}{c}\text { SDP } \\
(\mathrm{n}=18)\end{array}$ & $\begin{array}{c}\text { NDP } \\
(\mathrm{n}=18)\end{array}$ & $\begin{array}{c}\text { STMR } \\
(\mathrm{n}=18)\end{array}$ & $\begin{array}{c}\text { HTMR } \\
(\mathrm{n}=18)\end{array}$ & & Dry period & Feeding level & $\begin{array}{l}\text { Dry period } \times \\
\text { feeding level }\end{array}$ \\
\hline \multicolumn{9}{|l|}{ DMI } \\
\hline $\mathrm{Wk}-6$ to $0(\mathrm{~kg} / \mathrm{d})$ & 9.9 & 15.5 & 13.0 & 12.4 & 0.59 & $<0.001$ & 0.5 & 0.4 \\
\hline Wk $1-4(\mathrm{~kg} / \mathrm{d})$ & 16.0 & 16.9 & 16.3 & 16.6 & 0.63 & 0.3 & 0.8 & 0.9 \\
\hline Wk 5-12 (kg/d) & 19.6 & 18.6 & 18.6 & 19.8 & 0.43 & 0.1 & 0.01 & 0.6 \\
\hline \multicolumn{9}{|l|}{$\mathrm{BCS}$} \\
\hline Wk 5-12 & 2.74 & 3.34 & 2.83 & 3.25 & 0.11 & $<0.001$ & 0.01 & 0.6 \\
\hline \multicolumn{9}{|l|}{$\mathrm{EB}^{3}$} \\
\hline Wk 1-4 (UFL/d) & -1.92 & 1.61 & -0.83 & 0.53 & 0.80 & $<0.001$ & 0.15 & 0.3 \\
\hline Wk 5-12(UFL/d) & 0.74 & 2.41 & 1.23 & 1.91 & 0.53 & 0.02 & 0.3 & 0.9 \\
\hline Nadir (UFL/d) & -5.9 & -2.1 & -5.2 & -2.8 & 1.05 & 0.004 & 0.07 & 0.9 \\
\hline Wk of EB nadir & 2.6 & 2.3 & 2.5 & 2.3 & 0.23 & 0.3 & 0.4 & 0.004 \\
\hline Wk to zero EB & 7.1 & 4.2 & 6.5 & 4.7 & 0.76 & 0.003 & 0.08 & 0.26 \\
\hline
\end{tabular}

${ }^{1} \mathrm{SDP}=$ standard 8-wk dry period; NDP $=$ no planned dry period

${ }^{2} \mathrm{STMR}=$ standard TMR; HTMR $=$ high-quality TMR.

${ }^{3} \mathrm{UFL}=$ unité fourragère lait, unit of net energy, which is equivalent to $1 \mathrm{~kg}$ of standard air-dried barley.

postpartum DMI. Mean daily EB was greater in cows assigned to the NDP treatment compared with cows in the SDP treatment for wk 1 to 4 postpartum $(P$ $<0.001)$ and wk 5 to 12 postpartum $(P=0.02)$. The EB nadir was lower $(P=0.004)$ and the mean duration from parturition to return to zero EB was longer $(P=0.003)$ for cows in the SDP treatment compared with the NDP treatment. Cows assigned to the NDP treatment had greater BCS compared with SDP cows from wk 1 to 4 postpartum $(P=0.07)$ and wk 5 to 12 postpartum $(P<0.001)$.

There was no difference in DMI between cows assigned to the STMR diet compared with those assigned to the HTMR diet during wk 1 to $4(P=0.8)$, but during wk 5 to 12 cows assigned to the HTMR diet had increased DMI compared with those on the STMR diet $(P=0.01)$. There was no difference in calculated EB between cows on the HTMR and STMR diets during either wk 1 to 4 or wk 5 to 12 . The EB nadir tended to be lower $(P=0.07)$ and the duration from parturition to return to zero EB tended to be longer $(P=0.08)$ for cows on the STMR diet compared with cows on the HTMR diet. There was no effect of diet on BCS during wk 1 to 4 postpartum, but cows fed the HTMR diet had greater BCS during wk 5 to 12 compared with cows fed the STMR diet $(P=0.01)$.

\section{Plasma Insulin, IGF-I, and Metabolites}

The cows in the NDP treatment had greater circulating concentrations of glucose $(P<0.001)$, insulin $(P<$ $0.001)$, and IGF-I $(P=0.004)$ during the transition pe- riod compared with cows in the SDP treatment (Figure 1 ), whereas cows assigned to the SDP treatment had greater $(P=0.009)$ NEFA concentrations compared with cows in the NDP treatment (Table 4). During the posttransition period, cows assigned to the NDP treatment had increased circulating IGF-I concentrations compared with cows assigned to the SDP treatment $(P=0.02)$, whereas cows in the SDP treatment had greater circulating NEFA concentrations $(P=0.02)$. There were no differences between the dry period treatments from wk 4 to 12 postpartum in plasma glucose or BHBA concentrations, but circulating insulin was greater $(P=0.02)$ in cows assigned to the NDP treatment compared with the SDP treatment (Table 4).

During the transition period, cows fed the HTMR diet had increased concentrations of glucose compared with cows fed the STMR diet $(P=0.001)$, whereas cows on the STMR diet had significantly greater concentrations of BHBA $(P<0.001)$. Circulating insulin concentrations were greater $(P=0.04)$ during the transition period for cows on the HTMR diet, but there was no effect of dietary energy density on plasma IGF-I concentrations. During the posttransition period, cows fed the HTMR diet had greater circulating concentrations of insulin $(P<0.001)$, glucose $(P<0.001)$, and urea $(P<0.001)$ compared with cows on the STMR diet. Cows on the STMR diet had increased circulating concentrations of NEFA $(P=0.05)$ and BHBA $(P<$ 0.001) compared with cows fed the HTMR diet during the posttransition period. Cows on the HTMR diet had greater circulating IGF-I concentrations $(P=0.006)$ compared with cows fed the STMR diet for wk 4 to 9 relative to parturition (Figure 2; Table 4). 


\section{Reproductive Hormones and Follicular Dynamics}

Cows assigned to the SDP treatment had greater mean FSH concentrations during d 1 to 10 postpartum $(P=0.006)$ and greater peak FSH concentrations $(P$ $=0.008)$ compared with those assigned to the NDP treatment (Figure 3). Dry period duration did not affect the interval from calving until peak circulating FSH concentrations $(5.1 \pm 0.5$ DIM vs. $4.6 \pm 0.4$ DIM, NDP vs. SDP, respectively; $P=0.4$,). There was a weak, but statistically significant, negative correlation between the diameter of the dominant follicle at the first postpartum ultrasound examination and the DIM when peak FSH occurred $(\mathrm{r}=-0.34 ; P=0.04)$. The follicle data recorded at the first postpartum ovarian ultrasound examination $(9.4 \pm 0.5$ DIM vs. $8.6 \pm 0.6$ DIM, NDP vs. SDP, respectively; $P=0.2$ ) is summarized in Table 5. There was no effect of dry period treatment on the number of small follicles observed $(P$ $=0.8$ ). At the same ultrasound examination, cows assigned to the SDP treatment had a greater number of medium-size follicles $(P=0.04)$, whereas cows assigned to the NDP treatment had a greater number of large follicles $(P=0.04)$.

Ovulation occurred later in cows assigned to the SDP treatment compared with cows assigned to the NDP treatment $(16.9 \pm 2.5$ DIM vs. $24.8 \pm 2.6$ DIM, NDP vs. SDP, respectively; $P=0.02$ ). This corresponded to $83.3,11.1$, and $5.6 \%$ of cows assigned to the NDP treatment having their first ovulation during the first, second, and third or later postpartum follicular waves, respectively, whereas for cows assigned to the SDP treatment these values were $64.7,23.5$, and $11.8 \%$, respectively.

For cows that had an ovulation during the first postpartum follicle wave, there was no effect of dry period duration on peak E2 concentrations, day postpartum when peak E2 occurred, maximum follicle diameter, or day postpartum when maximum follicle diameter was observed (results not shown). For cows that failed to ovulate the first postpartum follicle wave, follicles underwent atresia ( $\mathrm{n}=3$ and 3 ) or developed into follicular cysts $(\mathrm{n}=3$ and 0$)$ in SDP and NDP cows, respectively. There was no significant effect of dry period duration on calving to service interval, conception rate to first service, calving to conception interval, or overall pregnancy rate (Table 6 ).

There were no differences in FSH concentrations during d 1 to 10 postpartum $(0.27$ vs. $0.27 \mathrm{ng} / \mathrm{mL} ; P=$ $0.9)$, nor was there a difference in peak FSH concentration ( 0.46 vs. $0.45 \mathrm{ng} / \mathrm{mL} ; P=0.7$ ) between cows assigned to the HTMR and STMR diets. Dietary energy density did not affect the number of days from calving until peak circulating FSH concentration $(4.9 \pm 0.4 \mathrm{~d}$
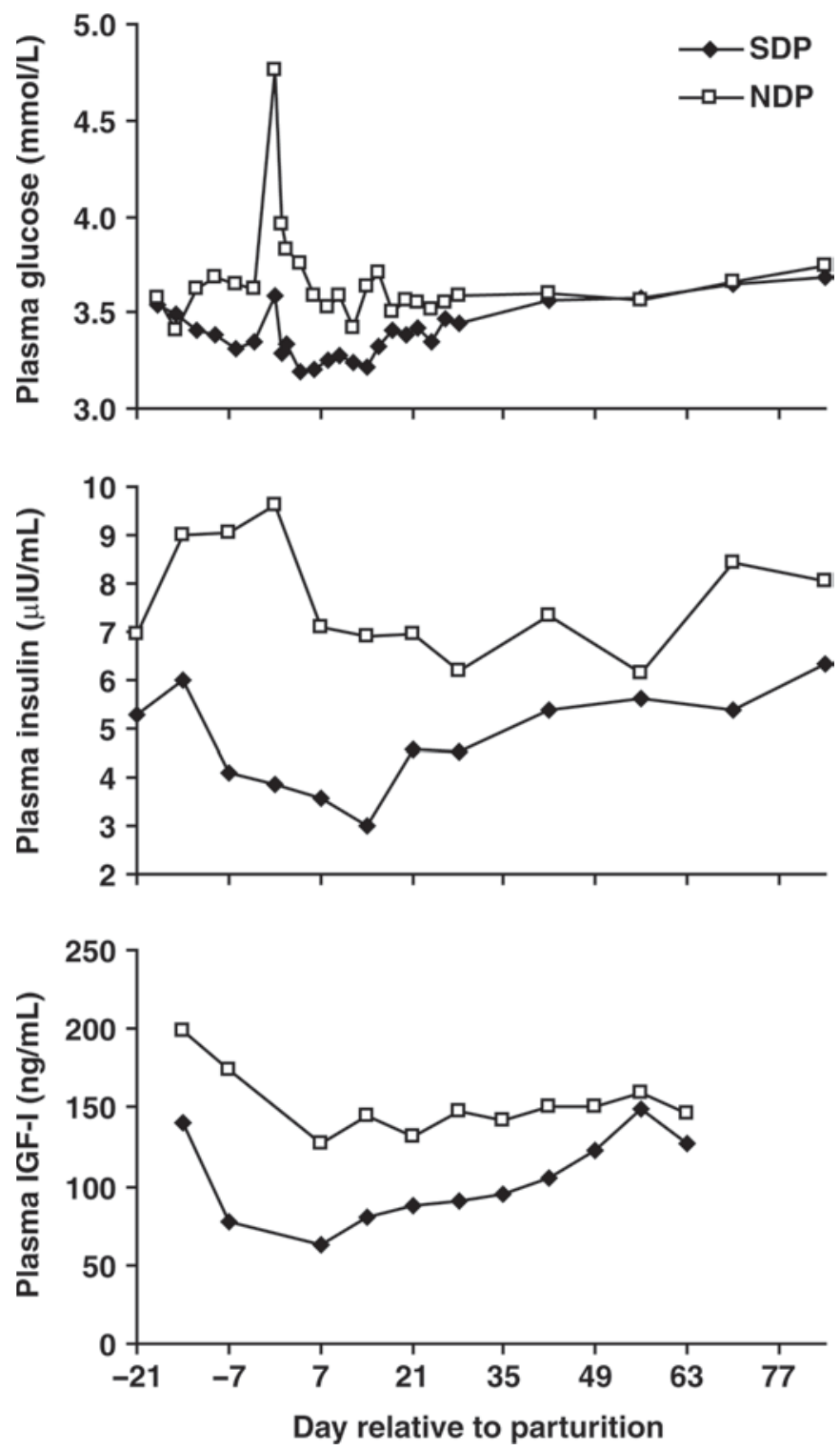

Figure 1. The effect of dry period duration on circulating glucose and insulin concentrations from wk -3 to 12 relative to parturition and IGF-I concentrations from wk -2 to 9 relative to parturition $(\mathrm{n}=18$ cows/treatment). Upper panel: Cows assigned to the no planned dry period (NDP) treatment had greater glucose concentrations compared with cows assigned to the standard 8-wk dry period (SDP) treatment during wk -3 to 3 relative to parturition $(P<0.001$; pooled $S E M=$ $0.04 \mathrm{mmol} / \mathrm{L})$ but not during wk 4 to 12 postpartum $(P=0.2$; pooled $\mathrm{SEM}=0.07 \mathrm{mmol} / \mathrm{L}$ ). Middle panel: Cows assigned to the NDP treatment had greater insulin concentrations compared with cows assigned to the SDP treatment during wk -3 to 3 relative to parturition $(P<$ 0.001 ; pooled $\mathrm{SEM}=0.62 \mu \mathrm{IU} / \mathrm{mL})$ and during wk 4 to $12(P=0.02$; pooled $\mathrm{SEM}=0.83 \mu \mathrm{IU} / \mathrm{mL}$ ). Lower panel: Cow assigned to the NDP treatment had greater IGF-I concentrations during wk -2 to 3 relative to parturition $(P=0.004$; pooled $\mathrm{SEM}=13.1 \mathrm{ng} / \mathrm{mL})$ and during wk 4 to $9(P=0.02$; pooled $\mathrm{SEM}=13.2 \mathrm{ng} / \mathrm{mL})$ postpartum compared with cows in the SDP treatment. 
Table 4. The effect of dry period duration and dietary energy density on the circulating metabolic hormones and metabolites from wk -3 to 3 and from wk 4 to 12 relative to parturition

\begin{tabular}{|c|c|c|c|c|c|c|c|c|}
\hline \multirow[b]{2}{*}{ Item } & \multicolumn{2}{|c|}{ Dry period ${ }^{1}$} & \multicolumn{2}{|c|}{ Feeding level $^{2}$} & \multirow[b]{2}{*}{ SEM } & \multicolumn{3}{|c|}{$P$-value } \\
\hline & $\begin{array}{c}\text { SDP } \\
(\mathrm{n}=18)\end{array}$ & $\begin{array}{c}\text { NDP } \\
(\mathrm{n}=18)\end{array}$ & $\begin{array}{c}\text { STMR } \\
(\mathrm{n}=18)\end{array}$ & $\begin{array}{l}\text { HTMR } \\
(\mathrm{n}=18)\end{array}$ & & $\begin{array}{c}\text { Dry } \\
\text { period }\end{array}$ & $\begin{array}{c}\text { Feeding } \\
\text { level }\end{array}$ & $\begin{array}{l}\text { Dry period } \times \\
\text { feeding level }\end{array}$ \\
\hline Glucose $(\mathrm{mmol} / \mathrm{L})$ & 3.35 & 3.69 & 3.43 & 3.61 & 0.04 & $<0.001$ & 0.001 & 0.4 \\
\hline Insulin $(\mu \mathrm{IU} / \mathrm{mL})^{\prime}$ & 4.37 & 7.94 & 5.35 & 6.97 & 0.62 & $<0.001$ & 0.04 & 0.14 \\
\hline $\mathrm{IGF}^{3} \mathrm{I}^{3}(\mathrm{ng} / \mathrm{mL})$ & 110 & 165 & 131 & 144 & 13.2 & 0.004 & 0.5 & 0.6 \\
\hline Urea $(\mathrm{mmol} / \mathrm{L})$ & 4.80 & 5.36 & 4.88 & 5.28 & 0.19 & 0.02 & 0.09 & 0.5 \\
\hline \multicolumn{9}{|l|}{ Posttransition period } \\
\hline Glucose $(\mathrm{mmol} / \mathrm{L})$ & 3.52 & 3.60 & 3.42 & 3.70 & 0.04 & 0.2 & $<0.001$ & 0.6 \\
\hline Insulin $(\mu \mathrm{IU} / \mathrm{mL})^{\prime}$ & 5.44 & 7.21 & 4.69 & 7.97 & 0.58 & 0.02 & $<0.001$ & 0.7 \\
\hline $\mathrm{IGF}^{-\mathrm{I}^{4}}(\mathrm{ng} / \mathrm{mL})$ & 114 & 150 & 109 & 155 & 13.2 & 0.02 & 0.006 & 0.7 \\
\hline NEFA (mmol/L) & 0.14 & 0.09 & 0.14 & 0.09 & 0.02 & 0.02 & 0.05 & 0.046 \\
\hline BHBA (mmol/L) & 0.48 & 0.41 & 0.54 & 0.35 & 0.04 & 0.2 & $<0.001$ & 0.12 \\
\hline
\end{tabular}

${ }^{1} \mathrm{SDP}=$ standard 8 -wk dry period; NDP $=$ no planned dry period.

${ }^{2} \mathrm{STMR}=$ standard TMR; HTMR $=$ high-quality TMR.

${ }^{3}$ IGF-I was measured from wk -2 to 3 relative to parturition.

${ }^{4}$ IGF-I was measured from wk 4 to 9 relative to parturition.

vs. $4.8 \pm 0.49$ d, HTMR vs. STMR, respectively). The follicle data recorded at the first postpartum ovarian ultrasound examination $(9.1 \pm 0.5$ DIM vs. $8.8 \pm 0.6$ DIM, HTMR vs. STMR, respectively; $P=0.6$ ) is summarized in Table 5. Cows on the STMR diet tended to have a greater number of small follicles $(P=0.07)$, but there were no differences between feeding level treatments in the number of medium follicles $(P=0.47)$ or large follicles $(P=0.87)$.

Dietary energy density did not affect the timing of the first postpartum ovulation $(20.8 \pm 2.7$ DIM vs. $20.9 \pm 2.5$ DIM, HTMR vs. STMR, respectively; $P$ $=0.9$ ). This corresponded to $73.7,10.5$, and $15.8 \%$ of cows assigned to the HTMR having their first ovulation during the first, second, and third or later postpartum follicular waves, respectively, whereas the values for cows assigned to the STMR were 70.6, 23.5, and 5.9\%, respectively.

For cows that had an ovulation during the first postpartum follicle wave, there was no effect of feeding level on peak E2 concentration, day postpartum when peak E2 occurred, maximum follicle diameter, or day postpartum when maximum follicle diameter was observed (results not shown). For cows that failed to ovulate the first postpartum follicle wave, follicles underwent atresia ( $\mathrm{n}=3$ and 2$)$ or developed into follicular cysts ( $\mathrm{n}=2$ and 2 ) in the HTMR and STMR treatments, respectively. Cows assigned to the STMR diet tended to have a greater conception rate to first service compared with cows on the HTMR diet (50.0 vs. $21.1 \%$, STMR vs. HTMR, respectively; $P=0.07$ ) but there was no effect of feeding level on the overall pregnancy rate at the end of the breeding period (Table 6).

\section{Interactions Between Dry Period Duration and Feeding Level}

Time of EB Nadir, Plasma NEFA, and BHBA. An interaction between dry period duration and feeding level was observed for the interval from parturition to the EB nadir. For cows in the NDP treatment, the HTMR diet resulted in a shorter interval from parturition to the EB nadir compared with the STMR diet $(2.86 \pm 0.30$ wk vs. $1.71 \pm 0.28$ wk; $P=0.03)$, but there was no effect of dietary feeding level for cows in the SDP treatment $(2.25 \pm 0.34$ wk vs. $2.88 \pm 0.27 \mathrm{wk}$; $P=0.4$ ). Similarly, cows in the SDP treatment had a longer interval to EB nadir compared with cows in the NDP treatment when fed the HTMR diet $(2.88 \pm$ 0.27 wk vs. $1.71 \pm 0.28$ wk; $P=0.02$ ), but there was no effect of dry period treatment when cows were fed the STMR diet $(2.25 \pm 0.34$ wk vs. $2.86 \pm 0.30 \mathrm{wk} ; P$ $=0.5$ ).

An interaction between dry period duration and feeding level was also observed for circulating NEFA concentrations (Figure 4). The HTMR diet decreased circulating NEFA concentrations for SDP cows $(0.32 \pm$ $0.05 \mathrm{mmol} / \mathrm{L}$ vs. $0.18 \pm 0.04 \mathrm{mmol} / \mathrm{L} ; P=0.03)$, but had no effect for NDP cows $(0.12 \pm 0.04 \mathrm{mmol} / \mathrm{L}$ vs. $0.19 \pm 0.04 \mathrm{mmol} / \mathrm{L} ; P>0.3)$ during the transition period (interaction between dry period length and feeding level; $P=0.003)$. Similarly, during the posttransition 

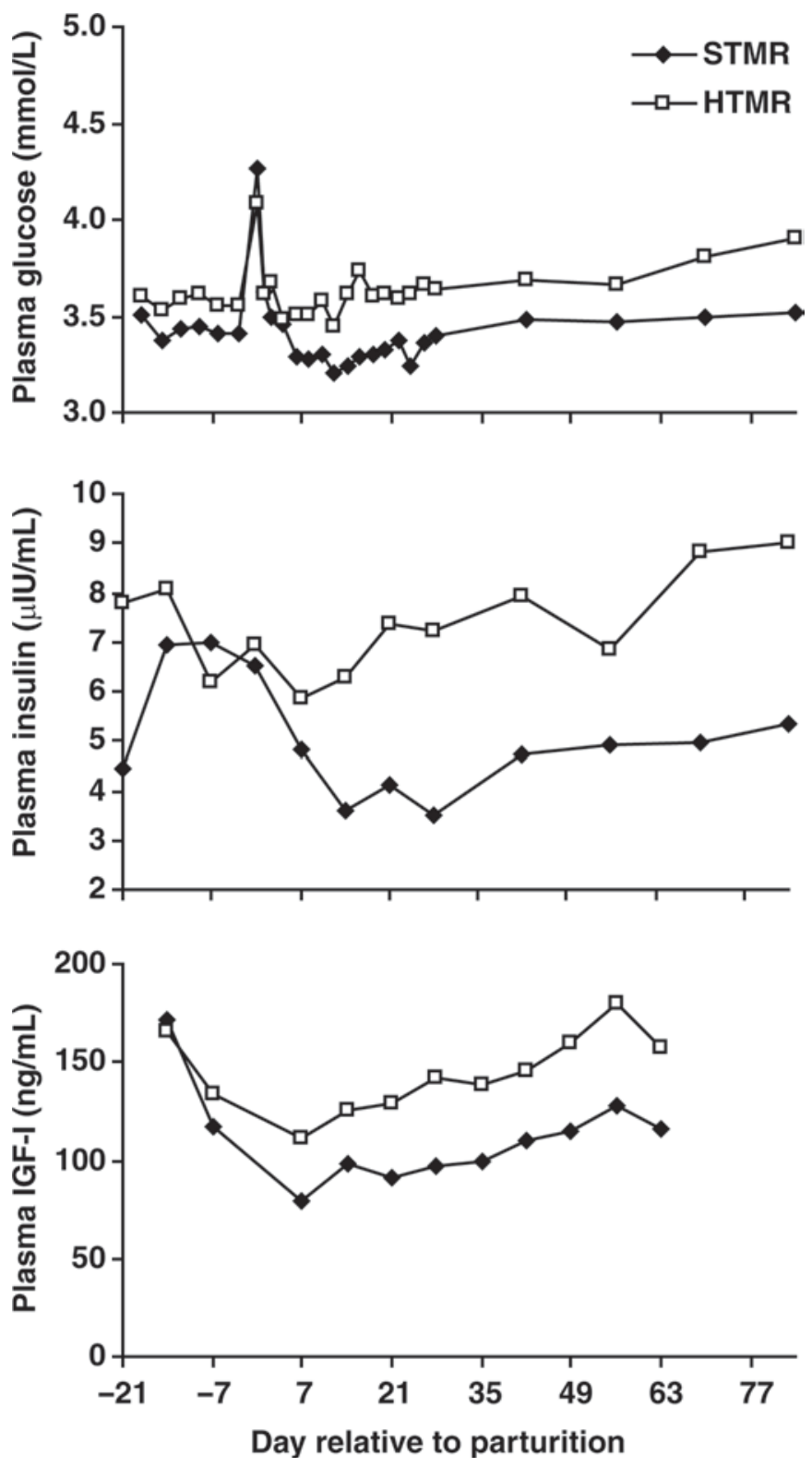

Figure 2. The effect of dietary energy density on circulating glucose and insulin concentrations from wk -3 to 12 relative to parturition and IGF-I concentrations from wk -2 to 9 relative to parturition ( $\mathrm{n}=18$ cows/treatment). Upper panel: Cows assigned to the highquality TMR (HTMR) diet had greater glucose concentrations during wk -3 to 3 relative to parturition $(P=0.001$; pooled $\mathrm{SEM}=0.04$ $\mathrm{mmol} / \mathrm{L})$ and during wk 4 to 12 postpartum $(P<0.001$; pooled SEM $=0.068 \mathrm{mmol} / \mathrm{L}$ ) than cows assigned to the standard TMR (STMR) diet. Middle panel: Cows assigned to the HTMR diet had greater plasma insulin concentrations during wk -3 to 3 relative to parturition $(P=0.04$; pooled SEM $=0.62 \mu \mathrm{IU} / \mathrm{mL})$ and from wk 4 to $12(P<$ 0.001 ; pooled $\mathrm{SEM}=0.43 \mu \mathrm{IU} / \mathrm{mL}$ ) than cows assigned to the STMR diet. Lower panel: There was no effect of diet on circulating IGF-I during wk -2 to 3 relative to parturition $(P=0.49$; pooled SEM $=$ $13.15 \mathrm{pg} / \mathrm{mL}$ ), but cows on the HTMR diet had greater plasma IGF-I concentrations compared with cows on the STMR diet during wk 4 to 9 postpartum $(P=0.006$; pooled SEM $=13.24 \mathrm{ng} / \mathrm{mL})$. period, HTMR decreased circulating NEFA concentrations for SDP cows $(0.19 \pm 0.03 \mathrm{mmol} / \mathrm{L}$ vs. $0.09 \pm$ $0.03 \mathrm{mmol} / \mathrm{L} ; P=0.04$ ), but had no effect for NDP cows $(0.08 \pm 0.03 \mathrm{mmol} / \mathrm{L}$ vs. $0.09 \pm 0.03 \mathrm{mmol} / \mathrm{L}$; $P>0.9)$, resulting in a significant interaction $(P=$ $0.045)$.

A similar interaction $(P=0.018)$ was observed for circulating BHBA concentrations during the transition period. The HTMR diet decreased circulating BHBA for cows in the SDP treatment $(0.64 \pm 0.05 \mathrm{mmol} / \mathrm{L}$ vs. $0.34 \pm 0.04 \mathrm{mmol} / \mathrm{L} ; P<0.001)$ but had no effect for cows in the NDP treatment $(0.52 \pm 0.04 \mathrm{mmol} / \mathrm{L}$ vs. $0.42 \pm 0.04 \mathrm{mmol} / \mathrm{L} ; P=0.3)$.

Preovulatory Circulating Estradiol-17 $\beta$. For cows that had an ovulatory first postpartum follicle wave, there were no significant effects of either dry period duration or feeding level on peak circulating E2 concentrations before ovulation. However, an interaction $(P=0.03)$ between dry period duration and feeding level was observed whereby cows assigned to the SDP treatment had significantly higher preovulatory peak E2 concentrations when fed the HTMR diet compared with cows fed the STMR diet. No effect of feeding level was observed for the cows assigned to the NDP treatment (Figure 5).

\section{DISCUSSION}

The main findings from this study are that 1) omitting the dry period or feeding a higher energy density TMR resulted in improved EB and metabolic status, but the improvements were achieved via different mechanisms; 2) postpartum plasma FSH concentrations and ovar-

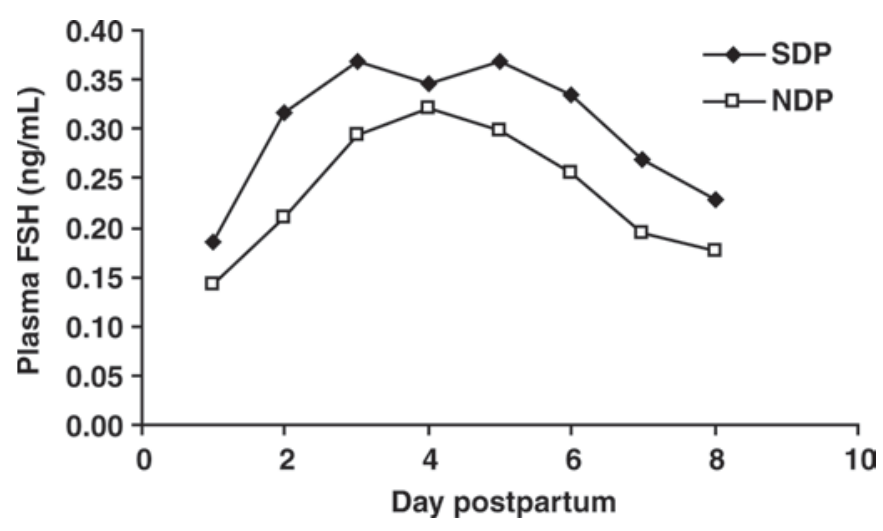

Figure 3. Effect of dry period duration on circulating FSH concentrations during the first $8 \mathrm{~d}$ postpartum $(\mathrm{n}=18 \mathrm{cows} /$ treatment $)$. Cows assigned to the standard 8-wk dry period (SDP) treatment had greater FSH concentrations than cows assigned to the no planned dry period $(\mathrm{NDP})$ treatment $(P=0.007$; pooled $\mathrm{SEM}=0.034 \mathrm{ng} / \mathrm{mL})$. 
Table 5. The effect of dry period duration and dietary energy density on the number of small, medium, and large follicles observed at the first postpartum ultrasound examination

\begin{tabular}{|c|c|c|c|c|c|c|c|c|}
\hline \multirow[b]{2}{*}{ Item } & \multicolumn{2}{|c|}{ Dry period $^{1}$} & \multicolumn{2}{|c|}{ Feeding level $^{2}$} & \multirow[b]{2}{*}{ SEM } & \multicolumn{3}{|c|}{$P$-value } \\
\hline & $\begin{array}{c}\text { SDP } \\
(\mathrm{n}=18)\end{array}$ & $\begin{array}{c}\text { NDP } \\
(\mathrm{n}=18)\end{array}$ & $\begin{array}{c}\text { STMR } \\
(\mathrm{n}=18)\end{array}$ & $\begin{array}{c}\text { HTMR } \\
(\mathrm{n}=18)\end{array}$ & & Dry period & Feeding level & $\begin{array}{c}\text { Dry period } \times \\
\text { feeding level }\end{array}$ \\
\hline Medium follicles & 5.0 & 3.3 & 4.4 & 3.8 & 0.86 & 0.05 & 0.5 & 0.9 \\
\hline Large follicles & 0.4 & 0.9 & 0.6 & 0.7 & 0.19 & 0.004 & 0.9 & 0.3 \\
\hline $\mathrm{DF}^{3}$ diameter & 10.0 & 11.3 & 10.3 & 10.9 & 0.78 & 0.16 & 0.5 & 0.7 \\
\hline
\end{tabular}

${ }^{1} \mathrm{SDP}=$ standard 8-wk dry period; NDP $=$ no planned dry period.

${ }^{2} \mathrm{STMR}=$ standard TMR; HTMR $=$ high-quality TMR.

${ }^{3} \mathrm{DF}=$ dominant follicle.

ian follicular development were affected by dry period duration; and 3) interval to first ovulation was reduced by omitting the dry period, but feeding a higher energy TMR had no effect. The results indicate that periparturient EB can be improved by altering management practices (e.g., dry period duration, feeding level). The results also suggest that improving EB or metabolic status per se will not necessarily result in an earlier onset of cyclicity.

Short dry periods reduce milk production in the subsequent lactation in several species, including cattle, rats, and humans (Annen et al., 2004); in cattle, this occurs because of reduced mammary epithelial cell turnover and secretory capacity (Annen et al., 2007). In the current study, average daily milk production during the first 12 wk of lactation was decreased by $16 \%$. Remond et al. (1997) reported that continuously milked cows had a $17 \%$ reduction in average daily milk yield, and Rastani et al. (2005) observed a $20 \%$ decrease in mean daily milk yield and a $16 \%$ decrease in SCM yield during the first $70 \mathrm{~d}$ postpartum in continuously milked cows. It should be noted that the milk production potential of the cows in the current study was similar to those in the report of Remond et al. (1997) but lower than the cows in the study reported by Rastani et al. (2005).
The cows assigned to the NDP treatment experienced only mild NEB for a short duration, and accordingly did not lose BCS postpartum. In contrast, the cows in the SDP treatment were in NEB for an average duration of $7.1 \mathrm{wk}$ following parturition, and on average lost 0.5 units of body condition. The improved EB status of the NDP cows was achieved via a reduction in milk energy output during the first 12 wk of lactation (2.4 UFL/d) while maintaining similar energy intake and maintenance requirements to cows in the SDP treatment. Similar to the cows in the NDP treatment, cows assigned to the HTMR diet did not lose BCS during the postpartum period. However, in contrast to the NDP treatment, the HTMR diet resulted in a nonsignificant increase in total milk energy output, a significant increase in energy intake, with an overall effect of a nonsignificant improvement in calculated EB. Hence, reducing the duration of the dry period decreased the inherent drive to produce milk in the subsequent lactation, whereas increasing dietary energy density allowed dietary energy intake to more closely meet energy requirements, albeit at a higher daily milk yield. During the first 12 wk postpartum, cows assigned to the NDP treatment had increased milk protein concentrations compared with cows in the SDP treatment. This is in agreement with previous reports that continuous

Table 6. The effect of dry period duration and dietary energy density on the reproductive performance of Holstein-Friesian cows during the breeding season

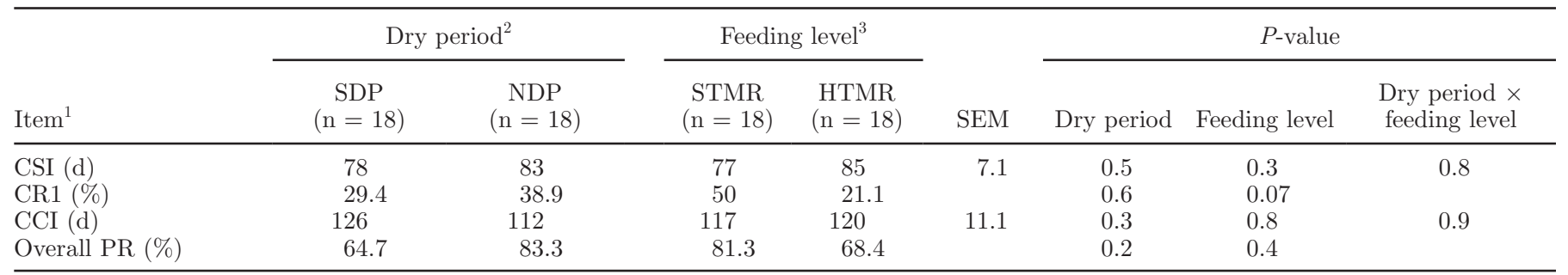

${ }^{1} \mathrm{CSI}=$ calving to service interval; $\mathrm{CR} 1=$ conception rate to first service; $\mathrm{CCI}=$ calving to conception interval; and $\mathrm{PR}=$ pregnancy rate

${ }^{2} \mathrm{SDP}=$ standard 8 -wk dry period; NDP $=$ no planned dry period.

${ }^{3} \mathrm{STMR}=$ standard TMR; HTMR $=$ high-quality TMR. 
milking results in higher milk protein concentrations (Remond et al., 1997; Rastani et al., 2005) and likely reflects their superior EB status. In contrast, the HTMR diet tended to increase milk protein concentration and resulted in a significant reduction in milk fat concentration. Reduced milk fat concentration is commonly observed with high-energy diets and is thought to be a result of rumen biohydrogenation intermediates exerting direct inhibitory effects on mammary milk fat synthesis (Bauman and Griinari, 2003).

Following expulsion of the fetal-placental unit and clearance of gestational steroids, plasma FSH concentrations increase within 3 to $5 \mathrm{~d}$ postpartum; this plays a pivotal role in orchestrating the emergence of a new follicular wave (Beam and Butler, 1997). In the current study, dietary energy density had no effect on postpartum FSH concentrations, but cows in the SDP treatment had greater concentrations of FSH compared with cows in the NDP treatment group. Gümen et al. (2005) reported that cows assigned to a continuous milking treatment had lower postpartum circulating FSH concentrations compared with cows on a traditional dry period treatment on d 6 postpartum. Those authors speculated that cows in an NDP treatment have their postpartum FSH surge earlier than d 6 postpartum, but this could not be detected because blood samples were not collected from d 1 to 6 postpartum in their experimental protocol. Our results do not support their hypothesis because we observed no differences in the timing of the postpartum FSH surge between the NDP and SDP treatment groups. Prepartum circulating E2 concentrations are reduced by omitting the dry period (Gümen et al., 2005) and could potentially affect postpartum pituitary release of FSH.

The greater circulating FSH concentrations observed in the SDP treatment group did not affect the number of small follicles at the first postpartum ultrasound examination. Interestingly, at the same ultrasound examination, the SDP treatment had a greater number of medium follicles $(5-10 \mathrm{~mm})$, whereas the NDP treatment had a greater number of large follicles $(>10 \mathrm{~mm})$. It is likely that this simply reflects a more advanced stage of follicle development, in that the cows in the NDP treatment had already developed a dominant follicle whereas the cows in the SDP treatment had several follicles at the selection stage of development. Our observations on follicle development are consistent with those of Gümen et al. (2005), who carried out the first postpartum scan on d 6 postpartum and reported a significantly larger mean follicle diameter for continuously milked cows compared with cows with a normal dry period. These data clearly indicate that increased circulating concentrations of FSH do not increase the rate of follicular development. A negative correlation
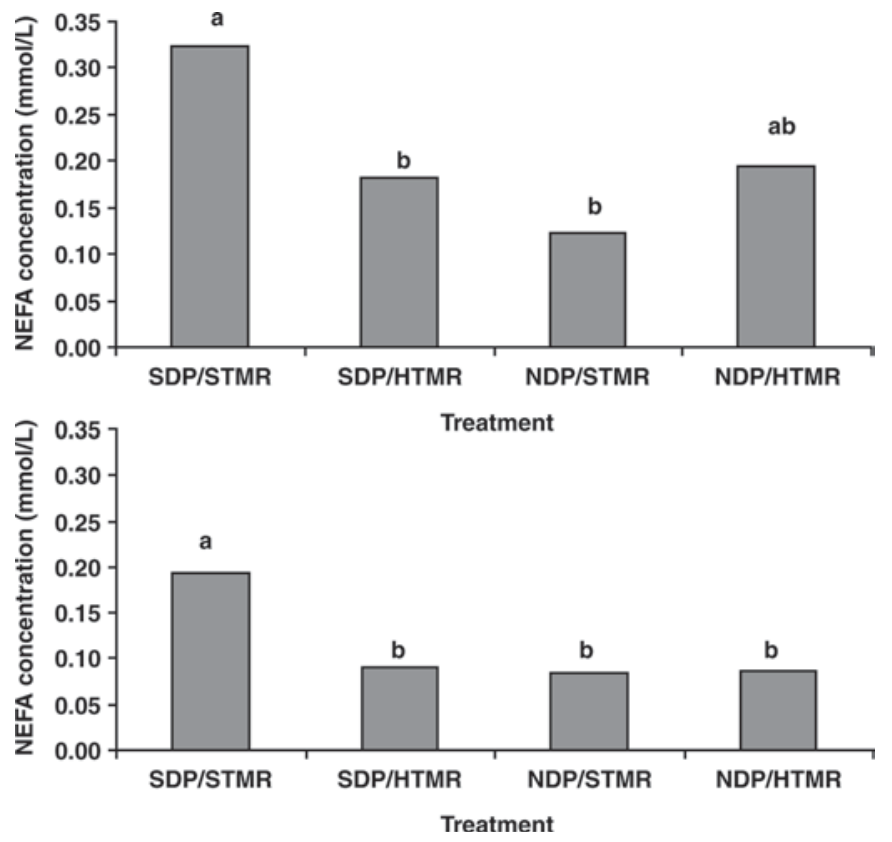

Figure 4. Effect of dry period duration and dietary energy density on NEFA concentrations. Upper panel: Circulating NEFA concentrations during wk -3 to 3 relative to parturition. Significant effects of dry period duration $(P=0.01)$ and the interaction between dry period duration and feeding level $(P=0.003)$ were observed. The effect of feeding level was not significant $(P=0.3)$. The pooled SEM was $0.03 \mathrm{mmol} / \mathrm{L}$. Lower panel: Circulating NEFA concentrations during wk 4 to 12 postpartum. Significant effects of dry period duration ( $P$ $=0.03)$, feeding level $(P=0.049)$, and the interaction between dry period duration and feeding level $(P=0.046)$ were observed. The pooled SEM was $0.02 \mathrm{mmol} / \mathrm{L}$. The number of cows per treatment was 8, 10, 9, and 9 for standard 8-wk dry period-standard TMR (SDP/ STMR), standard 8-wk dry period-high-quality TMR (SDP/HTMR), no planned dry period-standard TMR (NDP/STMR), and no planned dry period-high-quality TMR (NDP/HTMR), respectively. Letters a and $\mathrm{b}$ indicate that treatments not sharing a common letter differed at least $P<0.05$.

was observed between the diameter of the dominant follicle at the first postpartum ultrasound examination and the day postpartum when peak FSH concentration occurred. Hence, the earlier the postpartum increase in FSH concentrations occurred, the greater the size of the dominant follicle on $\mathrm{d} 8$ to 10 postpartum. This is consistent with previous reports indicating that emergence of the first follicle wave postpartum is related to the timing of the postpartum FSH surge (Beam and Butler, 1997). Despite not observing differences in the timing of peak FSH concentrations between either the dry period duration or dietary energy density treatments, the first postpartum ovulation occurred earlier for cows in the NDP treatment compared with cows in the SDP treatment, but dietary energy density had no significant effect.

Negative energy balance is associated with a decrease in circulating concentrations of insulin, glucose, and IGF-I, and increased circulating concentrations of NEFA 


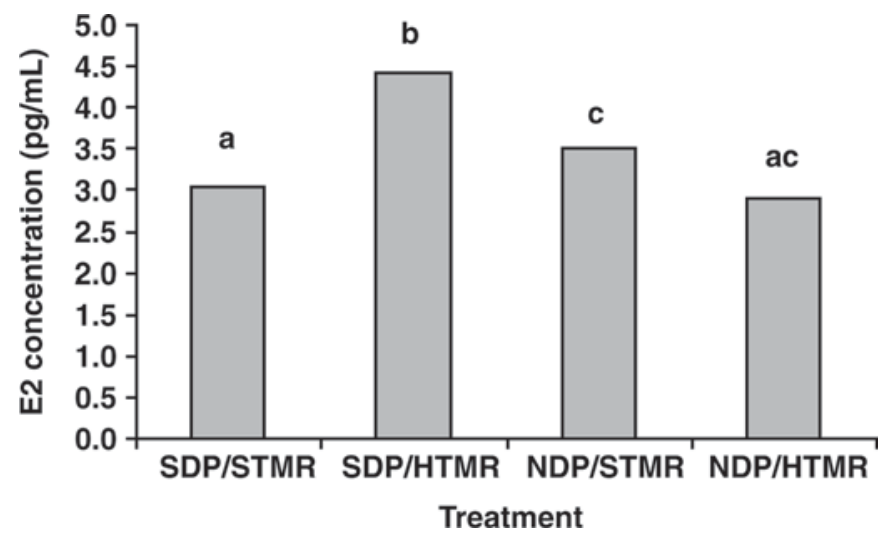

Figure 5. Effect of dry period duration and feeding level on peak circulating estradiol (E2) concentrations during the first postpartum follicular wave. A significant interaction between dry period duration and feeding level $(P=0.03)$ was observed, but the effects of dry period duration $(P=0.2)$ and feeding level $(P=0.4)$ were not significant. The pooled SEM was $0.46 \mathrm{pg} / \mathrm{mL}$. The number of cows per treatment was 8, 10, 9, and 9 for standard 8-wk dry period-standard TMR (SDP/STMR), standard 8-wk dry period-high-quality TMR (SDP/ HTMR), no planned dry period-standard TMR (NDP/STMR), and no planned dry period-high-quality TMR (NDP/HTMR), respectively. Letters $\mathrm{a}, \mathrm{b}$, and $\mathrm{c}$ indicate that treatments not sharing a common letter differed at least $P<0.05$.

and BHBA (Grummer, 1995). In the current study, cows in the NDP treatment had greater circulating insulin, glucose, and IGF-I concentrations, and lower circulating NEFA and BHBA concentrations compared with SDP cows, consistent with their superior EB status. Beam and Butler (1997) reported that circulating estradiol concentrations during the first postpartum follicle wave were greater and interval to first ovulation was shorter in cows with increased circulating IGF-I concentrations. In the current study, we observed greater circulating IGF-I concentrations in cows in the NDP treatment compared with the SDP treatment, and also in cows on the HTMR diet compared with cows on the STMR diet. The cows assigned to the NDP treatment ovulated earlier compared with cows in the SDP treatment, but there was no difference in interval to first ovulation between cows on the 2 dietary energy density treatments, despite the differences in plasma IGF-I concentrations. Butler et al. (2004) reported that a 2.6-fold increase in circulating insulin during the first postpartum follicle wave resulted in increased concentrations of circulating IGF-I and E2 without any apparent change in LH pulse release. Despite observing differences in circulating insulin and IGF-I concentrations in the current study because of either omitting the dry period or increasing dietary energy density, circulating E2 concentrations during the first postpartum follicular wave were not affected. It should be noted that average daily milk yield in the current study was moderate; consequently, NEB was also moderate and a high proportion of cows in all treatments had an ovulatory first postpartum follicle wave.

Lucy et al. (1991) reported that as predicted EB increased during the first $25 \mathrm{~d}$ postpartum, there was a decrease in the average number of small follicles $(6-9$ $\mathrm{mm}$ ) and an increase in the average number of large follicles $(10-15+\mathrm{mm})$, indicating that small follicles mature to larger follicles earlier in cows in superior EB status. It is likely that the superior EB status and increased concentrations of insulin and IGF-I for cows in the NDP treatment resulted in greater LH pulse frequency (Canfield and Butler, 1990) and, accordingly, the cows in the NDP treatment had an earlier onset of cyclicity compared with cows in the SDP treatment. Interestingly, the HTMR diet also resulted in greater circulating concentrations of insulin and IGF-I, improved $\mathrm{BCS}$, and circulating metabolite concentrations indicative of superior EB. Despite this, feeding the HTMR diet did not advance the onset of cyclicity and tended to have a negative effect on subsequent conception rate to first service. It is plausible to hypothesize that the greater metabolic burden of increased milk output and greater liver blood flow caused by increased DMI increased steroid hormone clearance, but neither the milk production nor the DMI in the current study were high by the standards of the modern Holstein-Friesian dairy cow. Nevertheless, the observation of poorer reproductive performance with increased concentrate supplementation is not consistent with other reports from this research center or elsewhere (Horan et al., 2004; Pollott and Coffey, 2008) and may be an artifact of the small number of animals enrolled in the study.

\section{CONCLUSIONS}

The results indicate that omitting the dry period and feeding a higher energy density diet results in superior metabolic status. The improved bioenergetic status was achieved via contrasting mechanisms. Omitting the dry period reduced the drive to produce milk, whereas increasing the dietary energy density allowed the feed consumed to more closely meet energy requirements despite increased milk output. Omitting the dry period advanced the interval to first postpartum ovulation, whereas feeding a high-energy TMR had no effect on onset of cyclicity. This study clearly shows that events during the dry period and early lactation critically affect nutrient partitioning, metabolism, milk production, and the reproductive axis.

\section{ACKNOWLEDGMENTS}

The authors thank J. P. Murphy, J. Kenneally (both of Teagasc, Moorepark, Fermoy, Co. Cork, Ireland), 
and the Moorepark farm staff for management and care of the animals. The technical assistance of N. Galvin (Teagasc, Moorepark) and N. Hynes (University College Dublin, Ireland) is also appreciated. National Development Plan (Dublin, Ireland) funding is gratefully acknowledged.

\section{REFERENCES}

Annen, E. L., R. J. Collier, M. A. McGuire, and J. L. Vicini. 2004. Effect of dry period length on milk yield and mammary epithelial cells. J. Dairy Sci. 87(E-Suppl.):E66-E76.

Annen, E. L., A. C. Fitzgerald, P. C. Gentry, M. A. McGuire, A. V. Capuco, L. H. Baumgard, and R. J. Collier. 2007. Effect of continuous milking and bovine somatotropin supplementation on mammary epithelial cell turnover. J. Dairy Sci. 90:165-183.

Bachman, K. C., and M. L. Schairer. 2003. Invited review: Bovine studies on optimal lengths of dry periods. J. Dairy Sci. 86:30273037.

Bauman, D. E., and J. M. Griinari. 2003. Nutritional regulation of milk fat synthesis. Annu. Rev. Nutr. 23:203-227.

Beam, S. W., and W. R. Butler. 1997. Energy balance and ovarian follicle development prior to first ovulation postpartum in dairy cows receiving three levels of dietary fat. Biol. Reprod. 56:133142 .

Butler, S. T., S. H. Pelton, and W. R. Butler. 2004. Insulin increases $17 \beta$-estradiol production by the dominant follicle of the first postpartum wave in dairy cows. Reproduction 127:537-545.

Butler, S. T., S. H. Pelton, and W. R. Butler. 2006. Energy balance, metabolic status, and the first postpartum ovarian follicle wave in cows administered propylene glycol. J. Dairy Sci. 89:2938-2951.

Butler, W. R. 2003. Energy balance relationships with follicular development, ovulation and fertility in postpartum dairy cows. Livest. Prod. Sci. 83:211-218.

Butler, W. R., and R. D. Smith. 1989. Interrelationships between energy balance and postpartum reproductive function in dairy cattle. J. Dairy Sci. 72:767-783.

Canfield, R. W., and W. R. Butler. 1990. Energy balance and pulsatile LH secretion in early postpartum dairy cattle. Domest. Anim. Endocrinol. 7:323-330.

Crowe, M. A., V. Padmanabhan, N. Hynes, S. J. Sunderland, W. J. Enright, I. Z. Beitins, and J. F. Roche. 1997. Validation of a sensitive radioimmunoassay to measure serum follicle-stimulating hormone in cattle: Correlation with biological activity. Anim. Reprod. Sci. 48:123-136.

Enright, W. J., L. T. Chapin, W. M. Moseley, S. A. Zinn, M. B. Kamdar, L. F. Krabill, and H. A. Tucker. 1989. Effects of infusions of various doses of bovine growth hormone-releasing factor on blood hormones and metabolites in lactating Holstein cows. J. Endocrinol. 122:671-679.

Evans, R. D., P. Dillon, F. Buckley, D. P. Berry, M. Wallace, V. Ducrocq, and D. J. Garrick. 2006. Trends in milk production, calving rate and survival of cows in 14 Irish dairy herds as a result of the introgression of Holstein-Friesian genes. Anim. Sci. $82: 423-433$.

Grummer, R. R. 1995. Impact of changes in organic nutrient metabolism on feeding the transition dairy cow. J. Anim. Sci. 73:2820-2833.

Grummer, R. R.,, and R. R. Rastani. 2004. Why reevaluate dry period length? J. Dairy Sci. 87(E-Suppl.):E77-E85.
Gümen, A., R. R. Rastani, R. R. Grummer, and M. C. Wiltbank. 2005. Reduced dry periods and varying prepartum diets alter postpartum ovulation and reproductive measures. J. Dairy Sci. 88:2401-2411.

Horan, B., J. F. Mee, M. Rath, P. O'Connor, and P. Dillon. 2004 The effect of strain of Holstein-Friesian cow and feeding system on reproductive performance in seasonal-calving milk production systems. Anim. Sci. 79:453-467.

Jarrige, J. 1989. INRAtion v. 2.7: Microsoft computer program of ration formulation for ruminant livestock. J. Agabriel, P. Champciaux, and C. Espinasse, ed. CNERTA. Dijon, France.

Lucy, M. C., C. R. Staples, F. M. Michel, and W. W. Thatcher. 1991 Energy balance and size and number of ovarian follicles detected by ultrasonography in early postpartum dairy cows. J. Dairy Sci. 74:473-482.

McNamara, S., J. J. Murphy, M. Rath, and F. P. O'Mara. 2003. Effects of different transition diets on energy balance, blood metabolites and reproductive performance in dairy cows. Livest. Prod. Sci. 84:195-206.

O'Mara, F. 1997. A Net Energy System for Cattle and Sheep. Department of Animal Science and Production, Faculty of Agriculture, University College Dublin, Belfield, Dublin 4, Ireland.

Pollott, G. E., and M. P. Coffey. 2008. The effect of genetic merit and production system on dairy cow fertility, measured using progesterone profiles and on-farm recording. J. Dairy Sci. 91:3649-3660.

Prendiville, D. J., W. J. Enright, M. A. Crowe, L. Vaughan, and J. F. Roche. 1995. Immunization of prepubertal beef heifers against gonadotropin-releasing hormone: Immune, estrus, ovarian, and growth responses . J. Anim. Sci. 73:3030-3037.

Pryce, J. E., and R. F. Veerkamp. 2001. The incorporation of fertility indices in genetic improvement programmes. BSAS Occasional Publication 26:237-250.

Pryce, J. E., R. F. Veerkamp, R. Thompson, W. G. Hill, and G. Simm. 1997. Genetic aspects of common health disorders and measures of fertility in Holstein-Friesian dairy cows. Anim. Sci. 65:353-360.

Rastani, R. R., R. R. Grummer, S. J. Bertics, A. Gumen, M. C. Wiltbank, D. G. Mashek, and M. C. Schwab. 2005. Reducing dry period length to simplify feeding transition cows: Milk production, energy balance, and metabolic profiles. J. Dairy Sci. 88:10041014

Remond, B., J. Rouel, N. Pinson, and S. Jabet. 1997. An attempt to omit the dry period over three consecutive lactations in dairy cows. Ann. Zootech. 46:399-408.

Royal, M. D., A. O. Darwash, A. P. F. Flint, R. Webb, J. A. Woolliams, and G. E. Lamming. 2000. Declining fertility in dairy cattle: Changes in traditional and endocrine parameters of fertility. Anim. Sci. 70:487-501.

Spicer, L. J., W. B. Tucker, and G. D. Adams. 1990. Insulin-like growth factor-I in dairy cows: Relationships among energy balance, body condition, ovarian activity, and estrous behavior. J. Dairy Sci 73:929-937.

Tyrrell, H. F., and J. T. Reid. 1965. Prediction of the energy value of cow's milk. J. Dairy Sci. 48:1215-1223.

van Arendonk, J. A. M., R. Hovenier, and W. Boer. 1989. Phenotypic and genetic association between fertility and production in dairy cows. Livest. Prod. Sci. 21:1-12.

Villa-Godoy, A., T. L. Hughes, R. S. Emery, L. T. Chapin, and R. L. Fogwell. 1988. Association between energy balance and luteal function in lactating dairy cows. J. Dairy Sci. 71:1063-1072. 